may be related to this oestrogenic property. We have studied the biological effects of tamoxifen in the rat and found that the compound can inhibit the stimulatory effects of concomitantly administered oestradiol in immature and ovariectomised rats, and similarly in mature animals it will inhibit the oestradiol-stimulated changes in the vaginal smear. What is of particular relevance is the fact that tamoxifen also produces atypical oestrogenic effects when administered alone. ${ }^{1}$

Radiolabelled tamoxifen has been shown to bind to the cytoplasmic oestrogen receptor ${ }^{3}$ and initiate the translocation of complexes to the cell nucleus" but, whereas oestradiol provokes cell division, the stimulatory effects of tamoxifen produce endometrial hypertrophy. The partial uterine growth which results is probably due to the inability of tamoxifen to provoke a prolonged and consistent rise in uterine DNA content. ${ }^{1}$ :

Similar effects have been observed in vitro using cultured human breast cancer cells, where it appears that non-steroidal antioestrogens in general, and tamoxifen in particular, have effects other than a simple antagonism of oestrogen action, as they can reduce the activity of some biochemical processes to below control values.

It is therefore apparent that, since tamoxifen can play a positive part in subcellular events as well as being an oestrogen antagonist, then any inappropriate biochemical changes which occur in mammary tumours may have a profound effect on continued growth and homoeostasis. Therefore, even though tamoxifen has the properties of an antioestrogen, its effects as a partial or atypical oestrogen agonist may be of prime importance for its antitumour activity in the post-menopausal patient with breast cancer.

V C JORDAN

Department of Pharmacology,

School of Medicine

Jordan, V C, Cancer Treatment Reports, 1976, 60, 1409

Jordan, V C, et al, Molecular and Cellular EndoJordan, V C, et al, M
crinology, 1977, 7 , 177.

Jordan, V C, and Prestwich, G, Molecular and Cellular

Endocrinology, 19778 , in press.
Lippman, M E, Bolan, G, and Huff, K, Cancer

Treatment Reports, 1976, 60, 1421.

\section{Chemoprophylaxis of malaria}

SIR,-In response to your leading article on chemoprophylaxis of malaria (20 November 1976, p 1215): In Kinshasa, Zaire, Plasmodium falciparum is found in perhaps $95 \%$ of the cases of malaria in the population. Malaria due to $P$ falciparum is easily diagnosed and treated. However, untreated, the morbidity and mortality are high.

Chloroquine is the antimalarial of choice in this area. Chloroquine in doses of 200$300 \mathrm{mg}$ per week is effective in preventing malaria. Chloroquine is effective in treating acute cases of falciparum malaria. The treatment is rapid, can be repeated, and the failure rate is low. The amount of chloroquine given must be determined by the age and weight of the patient. Here many patients have chronic haemolytic anaemia (sickle cell anaemia, etc ... .). These patients have increased folic acid requirements. They must receive additional folic acid to protect them against megaloblastic anaemia. Chloroquine apparently does not affect folic acid metabolism and does not increase folic acid requirements.
Chloroquine should be given weekly for life to patients who have had their spleens removed, whether for sound clinical reasons (trauma, etc) or for questionable, unsupported reasons (for example, sickle anaemia). After splenectomy for any cause there is an increased risk of cerebral malaria due to $P$ falciparum.

One final point: The myth that haemoglobin $S$ protects against malaria is simply not true, at least, not against falciparum malaria. The facts are: (1) that infection by $P$ falciparum results in many deaths in patients with sickle cell anaemia (homozygous S); (2) patients with sickle cell trait (haemoglobin A-S) may have repeated attacks of malaria due to $P$ falciparum. The frequency and severity of these attacks of malaria are the same as in those with haemoglobin A.

Service d'Hèmatologie

F A JoHnson

Institut de Médecine T

L'Hôpital Mama Yemo,

Kinshasa,

Zaire

\section{Royal College of Physicians and fluoridation}

SIR,-Mr R V Mummery (21 May, p 1352) points out that in a comparison of the DMF (decayed, missing, filled teeth) indices in adults over 30 years of age from an area of high $(1.4 \mathrm{ppm})$ and low $(0.25 \mathrm{ppm})$ concentration of naturally occurring fluoride in the drinking water the difference was negligible. He fails to remind your readers that the DMF index is not exclusively a measure of denta decay but includes (M) tooth loss from other causes. In young children the predominant cause of tooth loss is decay as reflected in the DMF values quoted of 3.9 (high fluoride) compared to $6 \cdot 6$ (low fluoride) in 5-year-old children.

However, there is a shift in the cause of tooth loss with increasing age. In adults the proportion of teeth lost because of decay falls, and other reasons for tooth extraction, such as periodontal disease and the patient's attitude to dental health are of increasing importance. ${ }^{1}: 3$

The fact that the beneficial effect of fluoridation is limited to reducing dental decay is undisputed. No claim has been made that fluoridation directly affects periodontal disease. Does $\mathrm{Mr}$ Mummery advocate that we refrain from reducing dental decay in children because they may develop periodontal disease as adults?

\section{Department of Oral Medicine}

and Pathology,

Glasgow Dental Hospital and School

Glasgow

Waerhaug, $\mathrm{J}$, in The Prevention of Periodontal Disease,

ed J E Eastoe, D C A Picton, and A G Alexander, ed J. London, Henry Kimpton, 1971 .

Gray, P G, et al, Adult Dental Health in England and W'ales in 1968 . London, HMSO, 1970.

Todd, J E, and Whitworth, A, Adult Dental Health
in Scotland, 1972. London, HMSO, 1974.

\section{Clinical rheumatology and orthopaedic} medicine

SIR,-Dr P W Blower (28 May, p 1413) hits the nail on the head when he deplores the inadequate provision for orthopaedic medicine. Surveys have shown that one patient in five visiting his family doctor has an orthopaedic non-surgical complaint. Hence it is evident that every orthopaedic team should include a medically orientated doctor dealing with the non-surgical lesions of the moving parts. This was the policy adopted at St Thomas's Hospital, where I was the orthopaedic physician. This collaboration worked well, each type of orthopaedic case being seen by an interested consultant. This arrangement exists today at the Strong Memorial Hospital, Rochester (NY), and again is popular on both sides.

What is now needed is an institute of orthopaedic medicine, ${ }^{1}$ where tuition can be offered all the year round to those anxious to learn this type of work and to physiotherapists who need to learn the appropriate manual methods. Within a year or two one physician could then be sent out to each orthopaedic team in the country, and the most expensive hiatus in our Health Service would be closed, not only on humanitarian grounds but for the benefit of insurance, industry, and sick-benefit funds. The institute exists on paper as a registered charity (secretary: G Symonds, 81 Belsize Lane, London NW3) but lacks funds to get started. Since very little capital outlay is required for orthopaedic medicine, and the clinic would pay for itself many times over, it presents an immediately feasible measure to deal with Dr Blower's fully justified criticism. In Spain Conesa' describes how, when he incorporated the methods of orthopaedic medicine at his rehabilitation centre, its annual cost fell from 24 to 6 million pesetas, and $47 \%$ of the patients got well in one treatment.

JAMES CYRIAX Visiting professor in orthopaedic medicine USA

' Cyriax, J H, Textbook of Orthofaedic Medicine, Vol 1, 6 th edn. London, Ballière Tindall, 1975. 2 Conesa, S H, Incorporaciòn de la Medicina ortopedica Fasc 1 .

\section{Anaesthetic waste gas scavenging systems}

SIR,-I was pleased to see that Professor L Rendell-Baker and Dr R A Milliken (21 May, $p$ 1348) have come to the same conclusion as we did here (19 February, p 506), that active extraction is to be preferred to passive, but I am puzzled by their statement that active systems "are very expensive in terms of energy costs." The DHSS Circular (HC (76)38) on the subject calls for an extraction rate of $301 / \mathrm{m}$ with a negative pressure not exceeding $1 \mathrm{~cm} / \mathrm{H}, \mathrm{O}$. Taking this to be $100 \mathrm{~Pa}$, a simple calculation shows that the theoretical power requirements are 0.005 watt. On the most pessimistic assumptions about losses in the pipe line and low-efficiency extraction pumps it is hard to see how the power requirement per patient could exceed 1 watt, or how this could disturb the most ardent conservationist.

This is not a trivial matter, because the belief that an active extraction system would be expensive was at least partly responsible for the DHSS recommendation that a passive system should be preferred. A similar nonquantitative approach has led to the belief that the scavenged gases could constitute a fire hazard and a chemical hazard to the pumps. A simple calculation again shows that if, as it should be, the expired air is diluted at the point of extraction the mixture could not possibly be flammable, and the possible halothane 
concentrations are several orders of magnitude below those which may cause trouble with oil immersed pumps.

It is to be hoped that the National Institutes of Health recommendations ${ }^{1}$ for acceptable limits are based on more reliable calculations, though it is difficult to see how dose-response curves can have been obtained from the available data.

Clinical Research Centre,

Watford Road

' Whitcher, C, et al, Development and Evaluation of Methods for Elimination of Waste Anesthetic Gases and. Washington DC, US Government Printing Office, 1975.

\section{Congenital dislocation of the hip}

SIR,-I would like to add two points to your leading article on the early diagnosis of congenital dislocation of the hip (21 May, p 1303).

Firstly, it needs to be emphasised that consistently successful detection at birth requires an enthusiast who is closely involved in the screening programme. Thus on a small scale, where one man has the opportunity to oversee the whole scheme, screening appears to be very effective ${ }^{1-4}$ in reducing the incidence of later presentation of the established dislocation. Wherever larger series have been reported over a widespread area" "screening has been less successful, and it is on this type of result that we must now be trying to improve.

Secondly, Fredersborg's experience, ' which you report, with abduction splintage in the neonate is not in common with most units in this country. These splints (a) cause avascular necrosis of the capital epiphysis in some cases and $(b)$ fail to control some dislocatable and dislocated hips. When assessing results of early splintage it has to be remembered that between five and 10 unstable hips at birth have to be detected and successfully treated to prevent one dislocated hip from presenting later on. Mitchell's ${ }^{\star}$ and Williamson's ${ }^{i}$ studies therefore show an incidence of late hip pathology which is almost unchanged.

M E CONYBEARE

Nuffield Orthopaedic Centre,

Oxford

Barlow, T G, fournal of Bone and foint Surgery, 1962,

44B,' 292.
2 Rosen, S von, fournal of Bone and foint Surgery, 1962, 44B, 284

Moore, F H, Paper presented at BOA Spring Meeting,

April 1977.
Hughes, J R, and Conybeare, M E, Study 1965-75,

Bjerkreim, I, Acta Orthopaedica Scandinavica, 1974 Suppl 157.

Williamson, J, fournal of Bone and foint Surgery, $1972,54 \mathrm{~B}, 13$

Fredensborg, N, fournal of Bone and foint Surgery, 1976, 58B, 272 . Mitchell, G P, fournal of Bone and foint Surgery, 1972,

\section{Hygiene in NHS hospitals}

SIR,-The letter (7 May, p 1215) on hygiene in National Health Service hospitals by Drs G A J Ayliffe and Mr B J Collins epitomises in our opinion the kind of attitude that has landed health authorities in the trouble they are in today in relation to food hygiene. While not wishing to enter into the argument of whether NHS hospitals should or should not be liable for prosecution, we find the reference to two sets of standards quite unacceptable. To suggest that the regulations are anything other than common sense is unfair, and with the greatest respect to those working in hospital infectious diseases units we are not convinced that they are the best people to advise on food hygiene matters, and in any case, if they are, what have they been doing all these years to permit the present state of affairs?

We note in the letter that environmental health officers should be invited to inspect catering facilities but that any recommendation should then be considered by the "hospital authorities," who will decide on order of priority. This is nothing short of patronising.

It is recognised that it may be a question either of improving hygiene standards or developing an important facet of health care, but we consider that a planning committee should not arbitrarily defer recommendations of a professional officer who has been invited to make them without first giving that person a chance to explain his views. Indeed in this locality the chief environmental health officer has a permanent place on the health service control of infection committee.

HARVEY GORDON Community physician

Graham Aston Borough Environmental Health and Housing Officer

Epsom

We now only have 10 beds and at least 20 part-time consultants sharing them. Since we are now allowed at any time to exceed 10 beds we cannot achieve $100 \%$ bed occupancy, and thus we will probably lose more at the next round of cuts. I ask the unions, the Government, and the Health Service Board what they think they are achieving. The Health Service Board particularly and the Minister are acting with blind haste in their application of the Health Services Act. The outcome will be no improvement in the National Health Service, disgruntled senior doctors demanding more National Health Service money to make up for lost private practice, and consultants spending more time away from their National Health Service bases.

Please tell me, Mr Fisher and others, if you read this journal, even if your intentions were honourable, do you not think you have got it wrong ? If you do admit this it may not be too late to revise the situation.

E FIELD

Chairman of the Subcommittee of Private Practice to the Greenwich

London SE18

\section{Refusal of award}

SIR,-Having read David Loshak's article in the Daily Telegraph of 27 May concerning the report of the Independent Pay Review Body I was encouraged to read that the Hospital Consultants and Specialists Association would refuse to accept the award and would return it to the Government, starting pay negotiations afresh on 1 August. From a tactical point of view it would be an advantage if the BMA did the same thing for the rest of the profession. This would probably enable us (1) to get a higher award in the next round, and (2) being paid at the beginning of the "wage pay year" would be more advantageous than being paid at the end of it with inflation running at $17^{\circ}$ ", a year.

An alternative approach would be to put the squeeze on ourselves, refuse derisory pay awards altogether, and beat the Government at their own game, thus precipitating the retirement for financial reasons of many elderly GPs, whose pay, which is inflationproof-linked, would be safeguarded. The resulting fall in the numbers of GPs would perhaps put pressure on the Government. This would be better than doctors going on strike or leaving the NHS, which most of us would find distasteful.

G R GenovesF

Salisbury

between consultants and junior staff.

Without private practice in National Health hospitals consultants would have to become either geographically part-time or fulltime, and yet they would be unable in many cases to fit more work into the week than they do at the present, and the Government would pay $2 / 11$ more in salaries for very little return. As Professor Harold Ellis pointed out (28 May, p 1408), the vacated beds will remain unfilled since their use depends on availability of medical and nursing staff and theatre space, etc.

Yet the squeeze on private practice in the National Health Service goes on. In our area we have lost $60 \%$ of our beds on the grounds that they were previously under used. If they were under used, what harm was private practice doing the National Health Service?

\section{Sudden blindness in polymyalgia arteritica}

SIR,-I agree with Drs A G Freeman and R W Ross Russell (28 May, p 1412), who remark that delay in commencing treatment of even a few hours may result in irreversible visual failure. This urgency is not widely appreciated, nor is the fact that blindness may be the first symptom of giant cell arteritis.

I have recommended ${ }^{\prime}$ that the treatment of any elderly patient who suddenly loses the sight of one or both eyes should be an immediate intravenous injection of dexamethasone $10 \mathrm{mg}$ given by the general practitioner. Then, as in a cardiac emergency, the patient 